\title{
Inelastic processes in collisions of lithium positive ions with hydrogen anions and atoms ${ }^{\star}$
}

\author{
Andrey K. Belyaev ${ }^{1,2, a}$, Svetlana A. Yakovleva ${ }^{1,2}$, and Wolfgang P. Kraemer ${ }^{2}$ \\ ${ }^{1}$ Department of Theoretical Physics and Astronomy, Herzen University, St. Petersburg 191186, Russia \\ 2 Max-Planck Institute for Astrophysics, Postfach 1371, 85741 Garching, Germany
}

Received 10 June 2017 / Received in final form 9 August 2017

Published online 7 November 2017

(C) The Author(s) 2017. This article is published with open access at Springerlink.com

\begin{abstract}
Inelastic processes in the low-energy collisions $\mathrm{Li}^{3+}+\mathrm{H}^{-}, \mathrm{Li}^{2+}+\mathrm{H}, \mathrm{Li}^{2+}+\mathrm{H}^{-}$and $\mathrm{Li}^{+}+\mathrm{H}^{2}$ are investigated for all collisional channels with the excited ionic lithium states $\mathrm{Li}^{2+}(n l)$ and $\mathrm{Li}^{+}(1 s n l)$ up to and including the corresponding ion-pair states for the temperature range $1000-20000 \mathrm{~K}$. For all possible processes in the $\mathrm{Li}^{3+}+\mathrm{H}^{-}$and $\mathrm{Li}^{2+}+\mathrm{H}$ collisions inelastic cross sections and rate coefficients are calculated for the transitions between the ion-pair channel $\mathrm{Li}^{3+}+\mathrm{H}^{-}$and the 35 below lying contributing $\mathrm{Li}^{2+}(n l)+\mathrm{H}$ channels. It is found that the highest values of cross sections and rate coefficients are obtained for the recombination processes and their inverse, the ion-pair formation processes, involving the $\mathrm{Li}^{2+}(3 l), \mathrm{Li}^{2+}(4 l)$, and $\mathrm{Li}^{2+}(5 l)$ states. For the processes in the $\mathrm{Li}^{2+}+\mathrm{H}^{-}$and $\mathrm{Li}^{+}+\mathrm{H}$ collisions, cross sections and rate coefficients are calculated for all transitions between $34 \mathrm{Li}^{+}(1 s n l)+\mathrm{H}$ channels lying below $\mathrm{Li}^{2+}+\mathrm{H}^{-}$plus this ion-pair channel. In this case the highest rate coefficients correspond to the recombination processes with the $\mathrm{Li}^{+}\left(1 s 3 l^{1,3} L\right)$ and $\mathrm{Li}^{+}\left(1 s 4 l^{1,3} L\right)$ final states, as well as their inverse processes of ion-pair production. Rate coefficient values for these most efficient processes are rather high, of the order of $10^{-8} \mathrm{~cm}^{3} / \mathrm{s}$. This leads to total recombination rate coefficients in $\mathrm{Li}^{3+}+\mathrm{H}^{-}$and $\mathrm{Li}^{2+}+\mathrm{H}^{-}$ collisions with values larger than $10^{-7} \mathrm{~cm}^{3} / \mathrm{s}$.
\end{abstract}

\section{Introduction}

Collisions of multiply charged ions with atoms, ions, molecules, clusters, fullerenes, and surfaces have attracted a great deal of attention for decades, see, e.g., [1-3]. This is motivated by the necessity of an understanding of fundamental inelastic collision dynamics, as well as the needs of detailed cross sections and rate coefficients in some other research fields. The latter include inelastic collision processes in interactions of charged ion beams with plasma in fusion experiments, as well as with a residual gas in an accelerator storage ring. Collisions with multiply charged ions are also important in astrophysics, for example, collisions of solar-wind ions with atomic systems from the interstellar media which lead to charge exchange, excitation and de-excitation processes. A special interest exists in collisions between positive and negative ions, in particular, with hydrogen anions, collisions leading to neutralization processes. Recently, this kind of interest has been growing up due to the experiments carrying out within the Double ElectroStatic Ion Ring ExpEriment (DESIREE) project [4,5], see also [6] for the CSR

\footnotetext{
* Supplementary material in the form of one zip file available from the Journal web page at https://doi.org/10.1140/epjd/e2017-80390-4.

a e-mail: andrey.k.belyaev@gmail.com
}

project and [7] for the RICE project. Among other processes, the experiments treat neutralization processes in collisions between cations and anions.

Lithium-hydrogen collisions are of interest, in particular, due to their importance for non-local thermodynamic equilibrium (non-LTE) modelings of cool stellar atmospheres (see, e.g., reviews [8-10], and references therein). It has been shown theoretically in reference [11] that the mutual neutralization processes $\mathrm{Li}^{+}+\mathrm{H}^{-} \rightarrow \mathrm{Li}(n l)+\mathrm{H}(1 s)$, as well as their inverse processes, the ion-pair production, are important for non-LTE modelings of lithium spectra in cool stellar atmospheres, which are in turn important for determining absolute and relative abundances of lithium. The mutual neutralization processes in $\mathrm{Li}^{+}+\mathrm{H}^{-}$collisions have been studied theoretically in references $[12,13]$; a maximum rate coefficient of the order of $10^{-7} \mathrm{~cm}^{3} / \mathrm{s}$ was obtained. The excitation and de-excitation processes in $\mathrm{Li}+\mathrm{H}$ collisions have been treated theoretically in reference [14]. Inelastic processes in collisions of multiply charged lithium ions with hydrogen atoms and anions are much less studied. Inelastic processes involving the ground and the lowlying molecular states of the $\mathrm{LiH}^{+}$quasi-molecule, that is, the states asymptotically correlated to the interactions $\mathrm{Li}^{+}+\mathrm{H}, \mathrm{Li}(2 s)+\mathrm{H}^{+}, \mathrm{Li}^{*}(n l=2 s, 2 p, 3 s, 3 p)+\mathrm{H}^{+}$, $\mathrm{Li}^{+}+\mathrm{H}^{*}(n=2,3)$ have been recently studied in theoretical papers $[15,16]$ (see also references therein). To the 
Table 1. $\mathrm{LiH}^{2+}\left({ }^{1} \Sigma^{+}\right)$scattering channels and asymptotic energies $(J$-average experimental values taken from NIST [29]) with respect to the asymptote of the ground-state $\mathrm{Li}^{2+}$ ion interacting with an $\mathrm{H}$ atom.

\begin{tabular}{lll}
\hline$j$ & $\mathrm{Scattering}^{2}$ atomic $)$ channels & Asymptotic energies $(\mathrm{eV})$ \\
\hline 1 & $\mathrm{Li}^{2+}\left(1 s^{2} S\right)+\mathrm{H}\left(1 s^{2} S\right)$ & 0.0000000 \\
2 & $\mathrm{Li}^{2+}\left(2 s^{2} S\right)+\mathrm{H}\left(1 s^{2} S\right)$ & 91.839612 \\
3 & $\mathrm{Li}^{2+}\left(2 p^{2} P\right)+\mathrm{H}\left(1 s^{2} S\right)$ & 91.841804 \\
4 & $\mathrm{Li}^{2+}\left(3 s^{2} S\right)+\mathrm{H}\left(1 s^{2} S\right)$ & 108.848175 \\
5 & $\mathrm{Li}^{2+}\left(3 p^{2} P\right)+\mathrm{H}\left(1 s^{2} S\right)$ & 108.848824 \\
6 & $\mathrm{Li}^{2+}\left(3 d^{2} D\right)+\mathrm{H}\left(1 s^{2} S\right)$ & 108.849403 \\
7 & $\mathrm{Li}^{2+}\left(4 s^{2} S\right)+\mathrm{H}\left(1 s^{2} S\right)$ & 114.801041 \\
8 & $\mathrm{Li}^{2+}\left(4 p^{2} P\right)+\mathrm{H}\left(1 s^{2} S\right)$ & 114.801315 \\
9 & $\mathrm{Li}^{2+}\left(4 d^{2} D\right)+\mathrm{H}\left(1 s^{2} S\right)$ & 114.801560 \\
10 & $\mathrm{Li}^{2+}\left(4 f^{2} F\right)+\mathrm{H}\left(1 s^{2} S\right)$ & 114.801664 \\
11 & $\mathrm{Li}^{2+}\left(5 s^{2} S\right)+\mathrm{H}\left(1 s^{2} S\right)$ & 117.556309 \\
12 & $\mathrm{Li}^{2+}\left(5 p^{2} P\right)+\mathrm{H}\left(1 s^{2} S\right)$ & 117.556449 \\
13 & $\mathrm{Li}^{2+}\left(5 d^{2} D\right)+\mathrm{H}\left(1 s^{2} S\right)$ & 117.556574 \\
14 & $\mathrm{Li}^{2+}\left(5 f^{2} F\right)+\mathrm{H}\left(1 s^{2} S\right)$ & 117.556628 \\
15 & $\mathrm{Li}^{2+}\left(5 g^{2} G\right)+\mathrm{H}\left(1 s^{2} S\right)$ & 117.556658 \\
16 & $\mathrm{Li}^{2+}\left(6 s^{2} S\right)+\mathrm{H}\left(1 s^{2} S\right)$ & 119.052973 \\
17 & $\mathrm{Li}^{2+}\left(6 p^{2} P\right)+\mathrm{H}\left(1 s^{2} S\right)$ & 119.053054 \\
18 & $\mathrm{Li}^{2+}\left(6 d^{2} D\right)+\mathrm{H}\left(1 s^{2} S\right)$ & 119.053126 \\
19 & $\mathrm{Li}^{2+}\left(6 f^{2} F\right)+\mathrm{H}\left(1 s^{2} S\right)$ & 119.053157 \\
20 & $\mathrm{Li}^{2+}\left(6 g^{2} G\right)+\mathrm{H}\left(1 s^{2} S\right)$ & 119.053174 \\
21 & $\mathrm{Li}^{2+}\left(6 h^{2} H\right)+\mathrm{H}\left(1 s^{2} S\right)$ & 119.053185 \\
22 & $\mathrm{Li}^{2+}\left(7 s^{2} S\right)+\mathrm{H}\left(1 s^{2} S\right)$ & 119.955402 \\
23 & $\mathrm{Li}^{2+}\left(7 p^{2} P\right)+\mathrm{H}\left(1 s^{2} S\right)$ & 119.955453 \\
24 & $\mathrm{Li}^{2+}\left(7 d^{2} D\right)+\mathrm{H}\left(1 s^{2} S\right)$ & 119.955499 \\
25 & $\mathrm{Li}^{2+}\left(7 f^{2} F\right)+\mathrm{H}\left(1 s^{2} S\right)$ & 119.955518 \\
26 & $\mathrm{Li}^{2+}\left(7 g^{2} G\right)+\mathrm{H}\left(1 s^{2} S\right)$ & 119.955529 \\
27 & $\mathrm{Li}^{2+}\left(7 h^{2} H\right)+\mathrm{H}\left(1 s^{2} S\right)$ & 119.955536 \\
28 & $\mathrm{Li}^{2+}\left(7 i^{2} I\right)+\mathrm{H}\left(1 s^{2} S\right)$ & 119.955541 \\
29 & $\mathrm{Li}^{2+}\left(8 s^{2} S\right)+\mathrm{H}\left(1 s^{2} S\right)$ & 120.541107 \\
30 & $\mathrm{Li}^{2+}\left(8 p^{2} P\right)+\mathrm{H}\left(1 s^{2} S\right)$ & 120.541142 \\
31 & $\mathrm{Li}^{2+}\left(8 d^{2} D\right)+\mathrm{H}\left(1 s^{2} S\right)$ & 120.541172 \\
32 & $\mathrm{Li}^{2+}\left(8 f^{2} F\right)+\mathrm{H}\left(1 s^{2} S\right)$ & 120.541185 \\
33 & $\mathrm{Li}^{2+}\left(8 g^{2} G\right)+\mathrm{H}\left(1 s^{2} S\right)$ & 120.541192 \\
34 & $\mathrm{Li}^{2+}\left(8 h^{2} H\right)+\mathrm{H}\left(1 s^{2} S\right)$ & 120.541197 \\
$\mathrm{Li}^{2+}\left(8 i^{2} I\right)+\mathrm{H}\left(1 s^{2} S\right)$ & 120.541200 \\
$\mathrm{Li}^{2+}\left(8 k^{2} K\right)+\mathrm{H}\left(1 s^{2} S\right)$ & 120.541203 \\
\hline & $\left.\mathrm{Li}^{-}\right)$ & 121.700155 \\
\hline
\end{tabular}

best of our knowledge, the processes involving higherlying states, that is, the states correlated to the $\mathrm{Li}^{+*}+\mathrm{H}$ and $\mathrm{Li}^{2+}+\mathrm{H}^{-}$channels, as well as the states correlated to the $\mathrm{Li}^{2+*}+\mathrm{H}$ and $\mathrm{Li}^{3+}+\mathrm{H}^{-}$channels, have not been treated so far. Since nowadays it is generally accepted that inelastic processes in heavy-particle collisions with hydrogen atoms and negative ions deserve more detailed consideration, especially, inelastic processes with high rate coefficients, this motivated us to study inelastic processes in collisions of lithium positive ions with hydrogen negative ions and neutral atoms. The interactions between multiply charged lithium ions and $\mathrm{H}^{-}$are obviously stronger compared to singly charged $\mathrm{Li}^{+}$and the corresponding collision processes are therefore expected to have higher rate coefficients.

Thus, in the present study, the role of the $\mathrm{H}^{-}$ion in collisions with the multiply charged lithium ions $\mathrm{Li}^{3+}$ and $\mathrm{Li}^{2+}$ is studied. For this purpose inelastic cross sections and rate coefficients for the charge-recombination (electron-transfer) processes as well as their inverse reactions, the ion-pair formation processes, according to $\mathrm{Li}^{Z+}+\mathrm{H}^{-} \rightleftharpoons \mathrm{Li}^{(Z-1)+}+\mathrm{H}$ (with $Z=3,2$ ) are investigated. In particular, for the recombination process in $\mathrm{Li}^{3+}+\mathrm{H}^{-}$collisions and its inverse the cross sections and rate coefficients for all transitions between the ionpair channel $\mathrm{Li}^{3+}+\mathrm{H}^{-}$and the below lying contributing $\mathrm{Li}^{2+}\left(n l^{2} L\right)+\mathrm{H}$ channels are determined (see Tab. 1). And similarly for $\mathrm{Li}^{2+}+\mathrm{H}^{-}$and $\mathrm{Li}^{+}+\mathrm{H}$ cross sections and rate coefficients are calculated for the transitions between the corresponding ion-pair channel and all the relevant below lying $\mathrm{Li}^{+}\left(1\right.$ snl $\left.{ }^{1,3} L\right)+\mathrm{H}$ channels (see Tab. 2).

Since the collision potentials between hydrogen and the highly excited ionic Li-states considered here are not accessible by rigorous ab initio calculations, a model potential approach discussed in the following section is applied here.

\section{Model approach}

In the present work, model estimates for inelastic cross sections and rate coefficients are obtained within the standard Born-Oppenheimer formalism, which is the most widely used and reliable approach for theoretical studies of low-energy heavy-particle collisions. The approach treats a collision problem in two steps: a fixed-nuclei electronic structure calculation and a nonadiabatic nuclear dynamical treatment.

The adiabatic potentials are estimated in the present work by means of the model asymptotic approach described in reference [17]. It has been justified by the full quantum calculations for several collisional systems involving hydrogen $[12,13,18-22]$ that the main mechanism of partial processes with high and moderate cross sections and rate coefficients is determined by the longrange ionic-covalent interactions. The model asymptotic approach [17] allows one to describe long-range nonadiabatic regions due to ionic-covalent interactions. In this case, nonadiabatic regions are passed by the system in a particular order and one can use the quantum multichannel model $[14,23-26]$ in order to treat a nonadiabatic nuclear dynamics. This model is advantageous because it is analytical. Comparison with the previous quantum calculations has shown that the model approach to nonadiabatic nuclear dynamics provides reasonable estimates for inelastic cross sections and rate coefficients with large and moderate values $[22,25]$.

The alternative approach for the nonadiabatic nuclear dynamics is the branching-probability-current method [17], which allows one to take into account not only long-range, but also short-range nonadiabatic regions, in particular, due to covalent-covalent interactions. It has been shown $[17,27]$ that inclusion of short-range regions practically does not change rate coefficients with the highest values, may affect up to some extent rate coefficients with moderate values, and usually changes markedly rate coefficients with low values. 


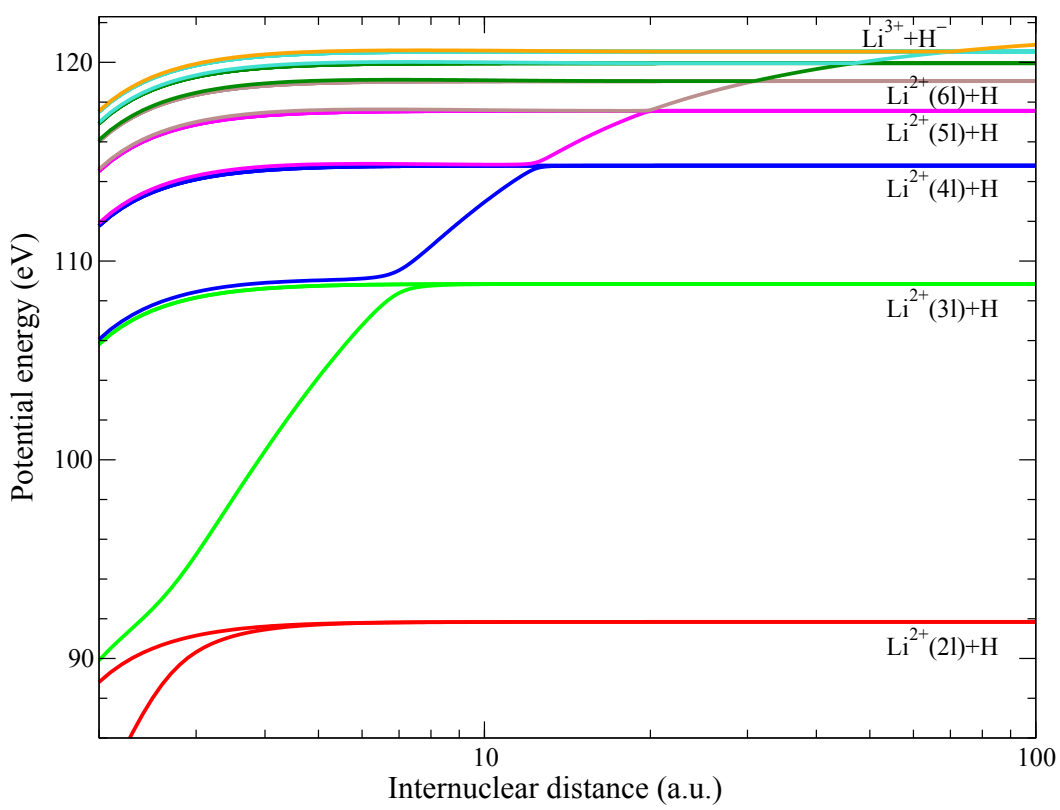

Fig. 1. The $\mathrm{LiH}^{2+}\left({ }^{1} \Sigma^{+}\right)$adiabatic potential energy curves obtained by means of the model approach. The potentials are measured from the ground state asymptote. The channels are defined in Table 1.

Since the main goal of the present paper is to calculate rate coefficients with the highest values, the multichannel model is employed in the present work based on the long-range (asymptotic) adiabatic potentials. Nonadiabatic transition probabilities in each nonadiabatic region are calculated within the Landau-Zener model by means of the adiabatic-potential-based formula $[17,28]$. Inelastic cross sections and rate coefficients for recombination, ionpair formation, excitation and de-excitation processes are then calculated as usual.

\section{Results for inelastic collisions $\mathrm{Li}^{3+}+\mathrm{H}^{-}$ and $\mathrm{Li}^{2+}(n l)+\mathrm{H}$}

The scattering channels treated in the present study of inelastic collisions $\mathrm{Li}^{3+}+\mathrm{H}^{-}$and $\mathrm{Li}^{2+}(n l)+\mathrm{H}$ are listed in Table 1. Since the ground ionic molecular state, which is responsible for inelastic transitions, has ${ }^{1} \Sigma^{+}$symmetry, only the scattering channels with this molecular symmetry are taken into account. Molecular states of other symmetries are not included in the present consideration.

The table also provides the asymptotic energies of the scattering channels. They are given relative to the $\mathrm{Li}^{2+}+\mathrm{H}$ asymptote for the molecular ion. The table shows that there is a large energy gap between this asymptote and the asymptote for the first excited state of the lithium ion $\mathrm{Li}^{2+}\left(2 s^{2} S\right)$ interacting with a hydrogen atom. In this gap an infinite number of Rydberg-like excited states $\mathrm{Li}^{2+}\left(1 s^{2} S\right)+\mathrm{H}(n l)$ and $\mathrm{Li}^{+}(1 s n l)+\mathrm{H}^{+}$exist $(n \geq 2)$. Above this group of Rydberg states the molecular states involving excited lithium ion states $\mathrm{Li}^{2+}\left(n l^{2} L\right)$ interacting with hydrogen atoms are located together with the ion-pair state $\mathrm{Li}^{3+}+\mathrm{H}^{-}$, as listed in Table 1. The two groups are energetically well separated, there are thus no nonadiabatic transitions between states belonging to the different groups. Transitions within each group can be studied independently. The present study treats nonadiabatic transitions between molecular states listed in Table 1 except the far low-lying $\mathrm{Li}^{2+}+\mathrm{H}$ asymptote.

It is also worth to mention that the treated states are located in the $\mathrm{Li}^{2+}\left(1 s^{2} S\right)+\mathrm{H}^{+}+e^{-}$continuum, so strictly speaking, these states are quasi-stationary. Nevertheless, using the approach from [30], it is possible to show that quasi-stationary widths of these states are negligible due to two-electron transitions and large internuclear distances. Thus, at the long-range distances, which are of the primary interest, the treated states can be considered as stationary, which is asymptotically exact.

The $\mathrm{LiH}^{2+}\left({ }^{1} \Sigma^{+}\right)$adiabatic potential energy curves calculated by the model approach described in the previous section are plotted in Figure 1. Short-range potentials estimated by this approach are not shown because only the long-range potentials determine essentially the lowenergy collision rate coefficients with large and moderate values. A series of avoided crossings due to the ionic-covalent interactions is clearly seen. Since the nonadiabatic regions are located in a particular order, the multichannel nuclear dynamical approach is applicable here. As described above, a nonadiabatic transition probability in each nonadiabatic region is calculated by means of the adiabatic-potential-based formula within the LandauZener model. The multichannel analytic formulae [26] are then used for computing an inelastic probability for each state-to-state transition. Finally, the inelastic cross sections and rate coefficients are calculated for all transitions between the scattering channels collected in Table 1.

Charge recombination rate coefficients for the $\mathrm{Li}^{3+}+$ $\mathrm{H}^{-}$collisions are calculated by the model approach described above. It turns out that among all possible partial recombination processes according to Table 1 the high rate coefficients of the order of $10^{-8} \mathrm{~cm}^{3} / \mathrm{s}$ are obtained 


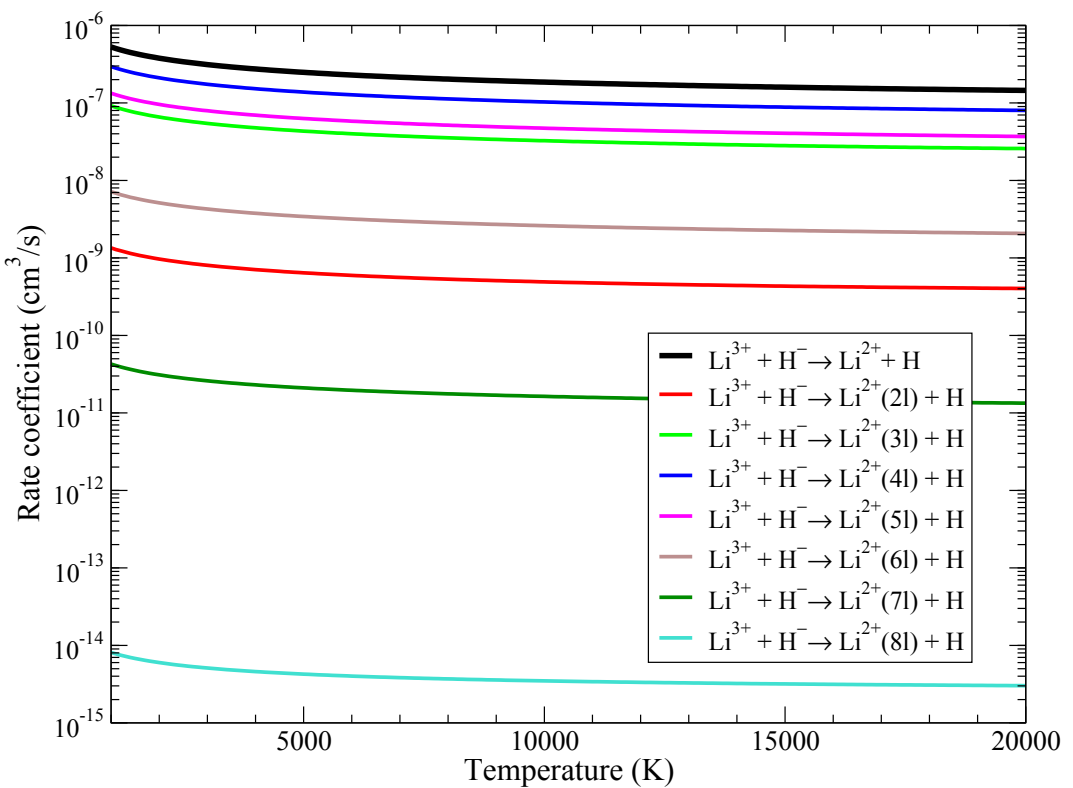

Fig. 2. Rate coefficients for the recombination processes in $\mathrm{Li}^{3+}+\mathrm{H}^{-}$collisions. The initial channel is ionic, the final channels are defined in Table 1. The thick black curve represents the total (summed over all final channels) rate coefficient. The colored lines show rate coefficients for a given $n$ of final channels $\mathrm{Li}^{2+}(n l)+\mathrm{H}$ summed over the quantum numbers $l$.

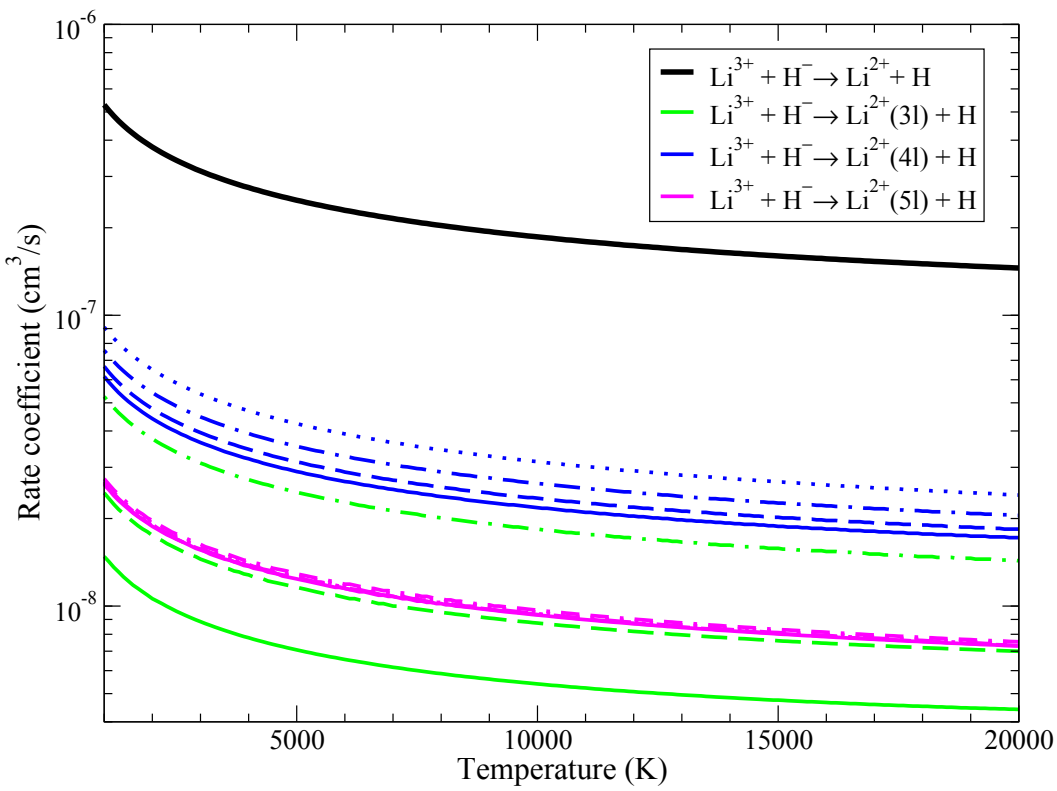

Fig. 3. The highest partial and total rate coefficients for recombination processes in $\mathrm{Li}^{3+}+\mathrm{H}^{-}$collisions. The solid lines represent $\mathrm{Li}^{2+}(n s)$ final states, the long-dashed lines $\mathrm{Li}^{2+}(n p)$, the dot-dashed $\mathrm{Li}^{2+}(n d)$, the dotted lines $\mathrm{Li}^{2+}(n f)$, the dot-double-dashed lines $\mathrm{Li}^{2+}(n g)$, the double-dot-dashed lines $\mathrm{Li}^{2+}(n h)$, the dashed lines $\mathrm{Li}^{2+}(n i)$.

only for a smaller group of processes whereas rate coefficients for the remaining recombination processes are separated from these by at least an order of magnitude, see Figure 2. Notice that this figure shows rate coefficients summed over quantum numbers $l$ at a given $n$ for the final channels. The temperature dependences of the recombination rate coefficients with the highest values corresponding to the partial processes into the $\mathrm{Li}^{2+}(3 l, 4 l, 5 l)$ final states are plotted in Figure 3 for a wide temperature range up to $T=20000 \mathrm{~K}$. Table 3 presents actual numerical rate coefficient values for these most intensively populated states in $\mathrm{Li}^{3+}+\mathrm{H}^{-}$and $\mathrm{Li}^{2+}(n l)+\mathrm{H}$ collisions at a temperature of $T=10000 \mathrm{~K}$. All the partial rate coefficients contribute to the total recombination rate coefficient exceeding $2 \times 10^{-7} \mathrm{~cm}^{3} / \mathrm{s}$. The highest rate coefficients for the partial recombination processes correspond to those processes leading to the $\mathrm{Li}^{2+}(4 l)$ final states. At $T=10000 \mathrm{~K}$ the rate coefficients for these states vary between $2.18 \times 10^{-8} \mathrm{~cm}^{3} / \mathrm{s}$ and $3.14 \times 10^{-8} \mathrm{~cm}^{3} / \mathrm{s}$. For recombination processes into 
Table 2. $\mathrm{LiH}^{+}\left({ }^{2} \Sigma^{+}\right)$scattering channels and asymptotic energies $(J$-average experimental values taken from NIST [29]) with respect to the ground state.

\begin{tabular}{|c|c|c|}
\hline$j$ & Scattering (atomic) channels & Asymptotic energies (eV) \\
\hline 1 & $\mathrm{Li}^{+}\left(1 s^{2}{ }^{1} S\right)+\mathrm{H}\left(1 s^{2} S\right)$ & 0.0000000 \\
\hline 2 & $\mathrm{Li}^{+}\left(1 s 2 s^{3} S\right)+\mathrm{H}\left(1 s^{2} S\right)$ & 59.020815 \\
\hline 3 & $\mathrm{Li}^{+}\left(1 s 2 s^{1} S\right)+\mathrm{H}\left(1 s^{2} S\right)$ & 60.922690 \\
\hline 4 & $\mathrm{Li}^{+}\left(1 s 2 p^{3} P\right)+\mathrm{H}\left(1 s^{2} S\right)$ & 61.280805 \\
\hline 5 & $\mathrm{Li}^{+}\left(1 s 2 p{ }^{1} P\right)+\mathrm{H}\left(1 s^{2} S\right)$ & 62.216335 \\
\hline 6 & $\mathrm{Li}^{+}\left(1 s 3 s^{3} S\right)+\mathrm{H}\left(1 s^{2} S\right)$ & 68.780785 \\
\hline 7 & $\mathrm{Li}^{+}\left(1 s 3 s^{1} S\right)+\mathrm{H}\left(1 s^{2} S\right)$ & 69.279627 \\
\hline 8 & $\mathrm{Li}^{+}\left(1 s 3 p^{3} P\right)+\mathrm{H}\left(1 s^{2} S\right)$ & 69.369302 \\
\hline 9 & $\mathrm{Li}^{+}\left(1 s 3 d^{3} D\right)+\mathrm{H}\left(1 s^{2} S\right)$ & 69.585346 \\
\hline 10 & $\mathrm{Li}^{+}\left(1 s 3 d^{1} D\right)+\mathrm{H}\left(1 s^{2} S\right)$ & 69.589059 \\
\hline 11 & $\mathrm{Li}^{+}\left(1 s 3 p{ }^{1} P\right)+\mathrm{H}\left(1 s^{2} S\right)$ & 69.648473 \\
\hline 12 & $\mathrm{Li}^{+}\left(1 s 4 s^{3} S\right)+\mathrm{H}\left(1 s^{2} S\right)$ & 71.908520 \\
\hline 13 & $\mathrm{Li}^{+}\left(1 s 4 s^{1} S\right)+\mathrm{H}\left(1 s^{2} S\right)$ & 72.108809 \\
\hline 14 & $\mathrm{Li}^{+}\left(1 s 4 p^{3} P\right)+\mathrm{H}\left(1 s^{2} S\right)$ & 72.144710 \\
\hline 15 & $\mathrm{Li}^{+}\left(1 s 4 d^{3} D\right)+\mathrm{H}\left(1 s^{2} S\right)$ & 72.234885 \\
\hline 16 & $\mathrm{Li}^{+}\left(1 s 4 d^{1} D\right)+\mathrm{H}\left(1 s^{2} S\right)$ & 72.237031 \\
\hline 17 & $\mathrm{Li}^{+}\left(1 s 4 f^{3} F\right)+\mathrm{H}\left(1 s^{2} S\right)$ & 72.238521 \\
\hline 18 & $\mathrm{Li}^{+}\left(1 s 4 f^{1} F\right)+\mathrm{H}\left(1 s^{2} S\right)$ & 72.238654 \\
\hline 19 & $\mathrm{Li}^{+}\left(1 s 4 p{ }^{1} P\right)+\mathrm{H}\left(1 s^{2} S\right)$ & 72.261723 \\
\hline 20 & $\mathrm{Li}^{+}\left(1 s 5 s^{3} S\right)+\mathrm{H}\left(1 s^{2} S\right)$ & 73.297506 \\
\hline 21 & $\mathrm{Li}^{+}\left(1 s 5 s^{1} S\right)+\mathrm{H}\left(1 s^{2} S\right)$ & 73.397349 \\
\hline 22 & $\mathrm{Li}^{+}\left(1 s 5 p^{3} P\right)+\mathrm{H}\left(1 s^{2} S\right)$ & 73.415303 \\
\hline 23 & $\mathrm{Li}^{+}\left(1 s 5 d^{3} D\right)+\mathrm{H}\left(1 s^{2} S\right)$ & 73.461173 \\
\hline 24 & $\mathrm{Li}^{+}\left(1 s 5 d^{1} D\right)+\mathrm{H}\left(1 s^{2} S\right)$ & 73.462426 \\
\hline 25 & $\mathrm{Li}^{+}\left(1 s 5 f^{3} F\right)+\mathrm{H}\left(1 s^{2} S\right)$ & 73.463130 \\
\hline 26 & $\mathrm{Li}^{+}\left(1 s 5 f{ }^{1} F\right)+\mathrm{H}\left(1 s^{2} S\right)$ & 73.463254 \\
\hline 27 & $\mathrm{Li}^{+}\left(1 s 5 p{ }^{1} P\right)+\mathrm{H}\left(1 s^{2} S\right)$ & 73.477364 \\
\hline 28 & $\mathrm{Li}^{+}\left(1 s 6 s^{3} S\right)+\mathrm{H}\left(1 s^{2} S\right)$ & 74.033686 \\
\hline 29 & $\mathrm{Li}^{+}\left(1 s 6 s^{1} S\right)+\mathrm{H}\left(1 s^{2} S\right)$ & 74.090542 \\
\hline 30 & $\mathrm{Li}^{+}\left(1 s 6 p^{3} P\right)+\mathrm{H}\left(1 s^{2} S\right)$ & 74.100775 \\
\hline 31 & $\mathrm{Li}^{+}\left(1 s 6 p{ }^{1} P\right)+\mathrm{H}\left(1 s^{2} S\right)$ & 74.122200 \\
\hline 32 & $\mathrm{Li}^{+}\left(1 s 6 d^{3} D\right)+\mathrm{H}\left(1 s^{2} S\right)$ & 74.127197 \\
\hline 33 & $\mathrm{Li}^{+}\left(1 s 6 d^{1} D\right)+\mathrm{H}\left(1 s^{2} S\right)$ & 74.127984 \\
\hline 34 & $\mathrm{Li}^{+}\left(1 s 6 f^{3} F\right)+\mathrm{H}\left(1 s^{2} S\right)$ & 74.128345 \\
\hline 35 & $\mathrm{Li}^{+}\left(1 s 6 f{ }^{1} F\right)+\mathrm{H}\left(1 s^{2} S\right)$ & 74.128475 \\
\hline$i$ & $\mathrm{Li}^{++}\left(1 s^{2} S\right)+\mathrm{H}^{-}\left(1 s^{2}{ }^{1} S\right)$ & 74.885893 \\
\hline
\end{tabular}

the $\mathrm{Li}^{2+}(3 l)$ states the rate coefficients are slightly lower, varying between $5.40 \times 10^{-9} \mathrm{~cm}^{3} / \mathrm{s}$ and $1.84 \times 10^{-8} \mathrm{~cm}^{3} / \mathrm{s}$ whereas for the processes ending in the $\mathrm{Li}^{2+}(5 l)$ final states they are in the range of $9 \times 10^{-9} \mathrm{~cm}^{3} / \mathrm{s}$.

Table 3 presents the rate coefficients at $T=10000 \mathrm{~K}$ for all transitions between the most intensively populated states in $\mathrm{Li}^{3+}+\mathrm{H}^{-}$and $\mathrm{Li}^{2+}(n l)+\mathrm{H}$ collisions. From the table it follows that the largest recombination rate coefficients are at least 20 times higher than the rate coefficients for excitation and de-excitation processes. At $T=10000 \mathrm{~K}$ the maximum rate coefficients for the de-excitation process $\mathrm{Li}^{2+}(4 s \rightarrow 3 d)+\mathrm{H}$ are equal to $8.68 \times 10^{-10} \mathrm{~cm}^{3} / \mathrm{s}$ whereas $6.67 \times 10^{-10} \mathrm{~cm}^{3} / \mathrm{s}$ for the excitation process $\mathrm{Li}^{2+}(4 s \rightarrow 4 p)+\mathrm{H}$. Rate coefficients for the ion-pair formation processes are at least 500 times smaller compared to the recombination processes. According to Table 3 the maximum ion-pair formation rate coefficient at $T=10000 \mathrm{~K}$ is equal to $1.90 \times 10^{-11} \mathrm{~cm}^{3} / \mathrm{s}$.
Obviously recombinations are much more efficient than any other processes in this collisional system.

Rate coefficients $K_{f i}$ for an endothermic ion-pair formation process $f \rightarrow i$ are evaluated here by the detailed balance relation using the rate coefficient $K_{i f}$ for the corresponding exothermic process $i \rightarrow f$ applying the following equation

$$
K_{f i}(T)=K_{i f}(T) \frac{p_{f}^{s t a t}}{p_{i}^{s t a t}} \exp \left(-\frac{\Delta E_{i f}}{k_{B} T}\right)
$$

$\Delta E_{i f}=E_{i}-E_{f}$ being the energy defect which is positive for an endothermic process $f \rightarrow i, p_{j}^{\text {stat }}$ a statistical probability of a channel $j$, and $k_{B}$ the Boltzmann constant. Equation (1) determines the temperature dependence of the ion-pair formation processes taking into account that the recombination rate coefficients are slowly varying with temperature.

The temperature dependence of the rate coefficients for the ion-pair formation processes as inverse of the corresponding most efficient recombination processes are plotted in Figure 4 for the temperature range up to $T=20000 \mathrm{~K}$. Due to the endothermicity of the ion-pair formation processes their rate coefficient curves have large energy thresholds and their maximum values are orders of magnitude smaller compared to their recombination equivalences. Actual numerical values at the temperature of $T=10000 \mathrm{~K}$ can be obtained from Table 3 .

The calculated partial rate coefficients for all processes in ionic-lithium-hydrogen collisions between the states listed in Table 1 are available online as supplementary materials to this paper.

It can be speculated here that at high enough $\mathrm{H}^{-}$ abundances the charge recombination processes $\mathrm{Li}^{3+}+$ $\mathrm{H}^{-} \rightarrow \mathrm{Li}^{2+}(n l)+\mathrm{H}$ can quickly lead to the formation of the excited ions $\mathrm{Li}^{2+}(3 l, 4 l, 5 l)$ due to the rather large charge recombination rate coefficients. The excited lithium ions will then produce ground-state lithium ions $\mathrm{Li}^{2+}$ in cascade transitions. If $\mathrm{H}^{-}$abundances are low, the electron recombination processes can produce excited ions $\mathrm{Li}^{2+}(n l)$, and the ion-pair formation processes in collisions of these ions with neutral hydrogen atoms efficiently create $\mathrm{H}^{-}$anions, which are important for many processes in astrophysics. In any case, charge recombination processes in $\mathrm{Li}^{3+}+\mathrm{H}^{-}$collisions and their inverse processes, the ion-pair formation, can possibly compete with electron recombination processes in the formation of lithium ions and atoms, as well as in the production of hydrogen negative ions.

\section{Results for inelastic collisions $\mathrm{Li}^{2+}+\mathrm{H}^{-}$ and $\mathrm{Li}^{+}(\mathbf{1 s n l})+\mathrm{H}$}

The ground ionic molecular state $\mathrm{Li}^{2+}+\mathrm{H}^{-}$has ${ }^{2} \Sigma^{+}$symmetry. Therefore, it is sufficient to treat nonadiabatic transitions only within this molecular symmetry when estimating inelastic cross sections and rate coefficients with high and moderate values. Similar to the previously discussed situation in $\mathrm{LiH}^{2+}$, there are two energetically 
Table 3. Rate coefficients, in units of $\mathrm{cm}^{3} / \mathrm{s}$, for the most important inelastic processes at $T=10000 \mathrm{~K}$, that is, for the recombination processes in $\mathrm{Li}^{3+}+\mathrm{H}^{-}$collisions, as well as for the ion-pair formation, excitation, and de-excitation processes in $\mathrm{Li}^{2+}(n l)+\mathrm{H}$ collisions. The labels for the initial and the final states are listed in Table 1.

\begin{tabular}{|c|c|c|c|c|c|c|c|}
\hline \multirow[t]{2}{*}{ Initial states } & \multicolumn{7}{|c|}{ Final states } \\
\hline & 4 & 5 & 6 & 7 & 8 & 9 & 10 \\
\hline \multicolumn{8}{|l|}{$T=10000 \mathrm{~K}$} \\
\hline 4 & - & $2.44 \mathrm{E}-10$ & $4.38 \mathrm{E}-11$ & $1.75 \mathrm{E}-13$ & $8.55 \mathrm{E}-14$ & $6.28 \mathrm{E}-14$ & $5.42 \mathrm{E}-14$ \\
\hline 5 & $8.13 \mathrm{E}-11$ & - & $7.46 \mathrm{E}-11$ & $1.16 \mathrm{E}-13$ & $5.50 \mathrm{E}-14$ & $3.99 \mathrm{E}-14$ & $3.42 \mathrm{E}-14$ \\
\hline 6 & $8.77 \mathrm{E}-12$ & $4.48 \mathrm{E}-11$ & - & $1.74 \mathrm{E}-13$ & $7.96 \mathrm{E}-14$ & $5.71 \mathrm{E}-14$ & $4.86 \mathrm{E}-14$ \\
\hline 7 & $1.75 \mathrm{E}-10$ & $3.47 \mathrm{E}-10$ & $8.68 \mathrm{E}-10$ & - & $6.67 \mathrm{E}-10$ & $4.22 \mathrm{E}-10$ & $3.38 \mathrm{E}-10$ \\
\hline 8 & $2.85 \mathrm{E}-11$ & $5.50 \mathrm{E}-11$ & $1.33 \mathrm{E}-10$ & $2.22 \mathrm{E}-10$ & - & $2.28 \mathrm{E}-10$ & $1.67 \mathrm{E}-10$ \\
\hline 9 & $1.26 \mathrm{E}-11$ & $2.39 \mathrm{E}-11$ & $5.70 \mathrm{E}-11$ & $8.44 \mathrm{E}-11$ & $1.37 \mathrm{E}-10$ & - & $1.76 \mathrm{E}-10$ \\
\hline 10 & $7.75 \mathrm{E}-12$ & $1.47 \mathrm{E}-11$ & $3.47 \mathrm{E}-11$ & $4.83 \mathrm{E}-11$ & $7.17 \mathrm{E}-11$ & $1.26 \mathrm{E}-10$ & - \\
\hline 11 & $3.47 \mathrm{E}-11$ & $6.13 \mathrm{E}-11$ & $1.38 \mathrm{E}-10$ & $1.32 \mathrm{E}-10$ & $1.49 \mathrm{E}-10$ & $1.7^{\prime}$ & $2.19 \mathrm{E}-10$ \\
\hline 12 & $9.38 \mathrm{E}-12$ & $1.65 \mathrm{E}-11$ & $3.68 \mathrm{E}-11$ & $3.45 \mathrm{E}-11$ & $3.89 \mathrm{E}-11$ & $4.58 \mathrm{E}-11$ & $5.64 \mathrm{E}-11$ \\
\hline 13 & $5.51 \mathrm{E}-12$ & $9.69 \mathrm{E}-12$ & $2.16 \mathrm{E}-11$ & $2.03 \mathrm{E}-11$ & $2.29 \mathrm{E}-11$ & $2.69 \mathrm{E}-11$ & $3.31 \mathrm{E}-11$ \\
\hline 14 & $3.89 \mathrm{E}-12$ & $6.83 \mathrm{E}-12$ & $1.52 \mathrm{E}-11$ & $1.43 \mathrm{E}-11$ & $1.61 \mathrm{E}-11$ & $1.89 \mathrm{E}-11$ & $2.33 \mathrm{E}-11$ \\
\hline 15 & $3.03 \mathrm{E}-12$ & $5.32 \mathrm{E}-12$ & $1.19 \mathrm{E}-11$ & $1.11 \mathrm{E}-11$ & $1.25 \mathrm{E}-11$ & $1.47 \mathrm{E}-11$ & $1.81 \mathrm{E}-11$ \\
\hline & & & & & & & \\
\hline
\end{tabular}

\begin{tabular}{lllllll}
\multirow{2}{*}{ Initial states } & \multicolumn{5}{c}{ Final states } \\
\cline { 2 - 7 } & 11 & 12 & 14 & 15 & $i$ \\
\hline$T=10000 \mathrm{~K}$ & & & & & & \\
4 & $1.42 \mathrm{E}-15$ & $1.15 \mathrm{E}-15$ & $1.13 \mathrm{E}-15$ & $1.11 \mathrm{E}-15$ & $1.11 \mathrm{E}-15$ & $4.50 \mathrm{E}-16$ \\
5 & $8.36 \mathrm{E}-16$ & $6.74 \mathrm{E}-16$ & $6.60 \mathrm{E}-16$ & $6.51 \mathrm{E}-16$ & $6.52 \mathrm{E}-16$ & $2.43 \mathrm{E}-16$ \\
6 & $1.13 \mathrm{E}-15$ & $9.04 \mathrm{E}-16$ & $8.85 \mathrm{E}-16$ & $8.73 \mathrm{E}-16$ & $8.74 \mathrm{E}-16$ & $3.07 \mathrm{E}-16$ \\
7 & $5.39 \mathrm{E}-12$ & $4.23 \mathrm{E}-12$ & $4.14 \mathrm{E}-12$ & $4.08 \mathrm{E}-12$ & $4.09 \mathrm{E}-12$ & $1.82 \mathrm{E}-12$ \\
8 & $2.04 \mathrm{E}-12$ & $1.59 \mathrm{E}-12$ & $1.56 \mathrm{E}-12$ & $1.53 \mathrm{E}-12$ & $1.54 \mathrm{E}-12$ & $6.52 \mathrm{E}-13$ \\
9 & $1.45 \mathrm{E}-12$ & $1.12 \mathrm{E}-12$ & $1.10 \mathrm{E}-12$ & $1.08 \mathrm{E}-12$ & $1.08 \mathrm{E}-12$ & $4.40 \mathrm{E}-13$ \\
10 & $1.28 \mathrm{E}-12$ & $9.88 \mathrm{E}-13$ & $9.66 \mathrm{E}-13$ & $9.51 \mathrm{E}-13$ & $9.52 \mathrm{E}-13$ & $3.74 \mathrm{E}-13$ \\
11 & - & $8.37 \mathrm{E}-11$ & $7.78 \mathrm{E}-11$ & $7.44 \mathrm{E}-11$ & $7.46 \mathrm{E}-11$ & $1.90 \mathrm{E}-11$ \\
12 & $2.79 \mathrm{E}-11$ & - & $2.89 \mathrm{E}-11$ & $2.71 \mathrm{E}-11$ & $2.73 \mathrm{E}-11$ & $6.36 \mathrm{E}-12$ \\
13 & $1.56 \mathrm{E}-11$ & $1.74 \mathrm{E}-11$ & - & $1.84 \mathrm{E}-11$ & $1.87 \mathrm{E}-11$ & $3.84 \mathrm{E}-12$ \\
14 & $1.06 \mathrm{E}-11$ & $1.16 \mathrm{E}-11$ & $1.31 \mathrm{E}-11$ & - & $1.70 \mathrm{E}-11$ & $2.77 \mathrm{E}-12$ \\
15 & $8.29 \mathrm{E}-12$ & $9.10 \mathrm{E}-12$ & $1.04 \mathrm{E}-11$ & $1.32 \mathrm{E}-11$ & - & $2.19 \mathrm{E}-12$ \\
$i$ & $9.32 \mathrm{E}-09$ & $9.35 \mathrm{E}-09$ & $9.42 \mathrm{E}-09$ & $9.52 \mathrm{E}-09$ & $9.68 \mathrm{E}-09$ & - \\
\hline
\end{tabular}

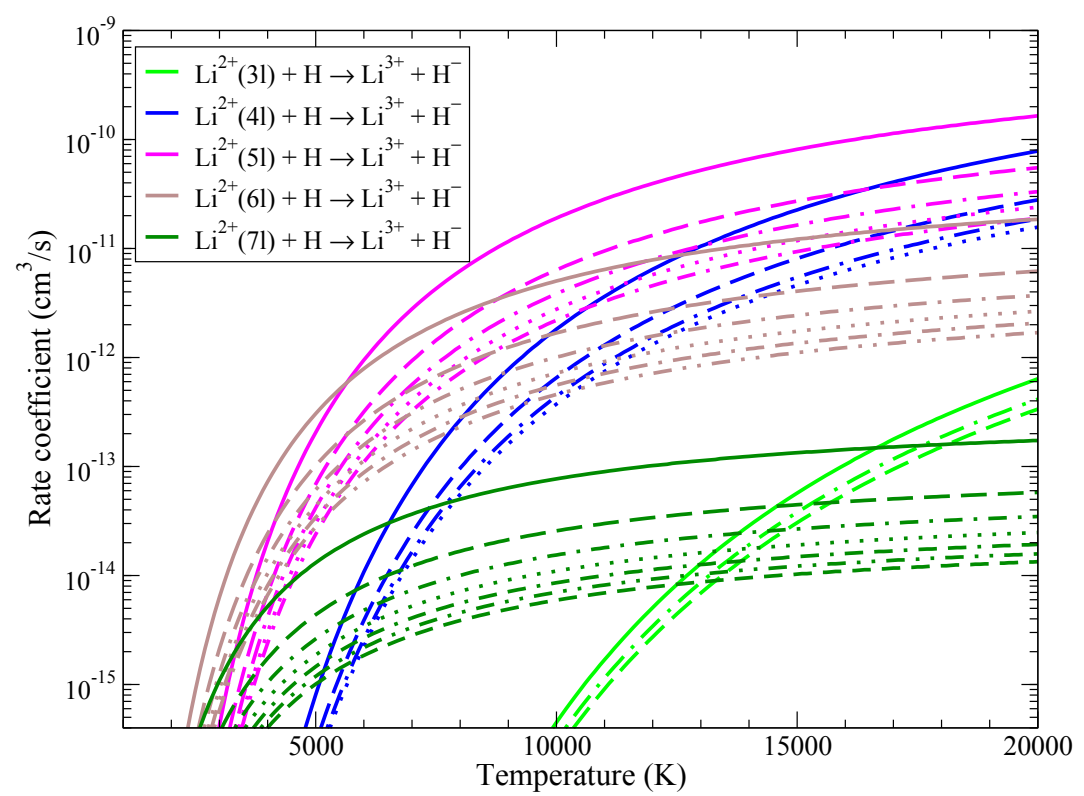

Fig. 4. The partial rate coefficients for ion-pair formation processes in $\mathrm{Li}^{2+}(n l)+\mathrm{H}$ collisions. The labels for the initial channels are the same as in Figure 3 for the final channels of the recombination processes. 
Table 4. Rate coefficients, in units of $\mathrm{cm}^{3} / \mathrm{s}$, for the most important inelastic processes at $T=10000 \mathrm{~K}$, that is, for the recombination processes in $\mathrm{Li}^{2+}+\mathrm{H}^{-}$collisions, as well as for the ion-pair formation, excitation, and de-excitation processes in $\mathrm{Li}^{+}(1 s n l)+\mathrm{H}$ collisions. The labels for the initial and the final channels are listed in Table 2 .

\begin{tabular}{|c|c|c|c|c|c|c|c|c|}
\hline \multirow[t]{2}{*}{ Initial states } & \multicolumn{8}{|c|}{ Final states } \\
\hline & 6 & 7 & 8 & 9 & 10 & 11 & 12 & 13 \\
\hline \multicolumn{9}{|c|}{$T=10000 \mathrm{~K}$} \\
\hline 6 & - & $1.01 \mathrm{E}-09$ & $1.91 \mathrm{E}-10$ & $5.44 \mathrm{E}-11$ & $1.76 \mathrm{E}-11$ & $7.13 \mathrm{E}-12$ & $6.10 \mathrm{E}-13$ & $3.83 \mathrm{E}-13$ \\
\hline 7 & $5.41 \mathrm{E}-09$ & - & $2.77 \mathrm{E}-09$ & $6.54 \mathrm{E}-10$ & $1.87 \mathrm{E}-10$ & $7.09 \mathrm{E}-11$ & $5.41 \mathrm{E}-12$ & $3.30 \mathrm{E}-12$ \\
\hline 8 & $1.26 \mathrm{E}-10$ & $3.42 \mathrm{E}-10$ & - & $3.07 \mathrm{E}-10$ & $6.80 \mathrm{E}-11$ & $2.27 \mathrm{E}-11$ & $1.43 \mathrm{E}-12$ & $8.35 \mathrm{E}-13$ \\
\hline 9 & $2.77 \mathrm{E}-11$ & $6.22 \mathrm{E}-11$ & $2.37 \mathrm{E}-10$ & - & $1.97 \mathrm{E}-10$ & $5.40 \mathrm{E}-11$ & $2.61 \mathrm{E}-12$ & $1.47 \mathrm{E}-12$ \\
\hline 10 & $2.70 \mathrm{E}-11$ & $5.37 \mathrm{E}-11$ & $1.58 \mathrm{E}-10$ & $5.94 \mathrm{E}-10$ & - & $6.35 \mathrm{E}-10$ & $2.00 \mathrm{E}-11$ & $1.07 \mathrm{E}-11$ \\
\hline 11 & $1.95 \mathrm{E}-11$ & $3.63 \mathrm{E}-11$ & $9.42 \mathrm{E}-11$ & $2.90 \mathrm{E}-10$ & $1.13 \mathrm{E}-09$ & - & $9.79 \mathrm{E}-11$ & $5.00 \mathrm{E}-11$ \\
\hline 12 & $2.30 \mathrm{E}-11$ & $3.81 \mathrm{E}-11$ & $8.15 \mathrm{E}-11$ & $1.93 \mathrm{E}-10$ & $4.91 \mathrm{E}-10$ & $1.35 \mathrm{E}-09$ & - & $8.52 \mathrm{E}-10$ \\
\hline 13 & $5.47 \mathrm{E}-11$ & $8.80 \mathrm{E}-11$ & $1.81 \mathrm{E}-10$ & $4.11 \mathrm{E}-10$ & $9.98 \mathrm{E}-10$ & $2.61 \mathrm{E}-09$ & $3.22 \mathrm{E}-09$ & - \\
\hline 14 & $5.39 \mathrm{E}-12$ & $8.58 \mathrm{E}-12$ & $1.73 \mathrm{E}-11$ & $3.88 \mathrm{E}-11$ & $9.26 \mathrm{E}-11$ & $2.37 \mathrm{E}-10$ & $2.64 \mathrm{E}-10$ & $3.74 \mathrm{E}-10$ \\
\hline 15 & $2.25 \mathrm{E}-12$ & $3.55 \mathrm{E}-12$ & $7.09 \mathrm{E}-12$ & $1.57 \mathrm{E}-11$ & $3.69 \mathrm{E}-11$ & $9.31 \mathrm{E}-11$ & $9.09 \mathrm{E}-11$ & $1.04 \mathrm{E}-10$ \\
\hline 16 & $6.27 \mathrm{E}-12$ & $9.83 \mathrm{E}-12$ & $1.95 \mathrm{E}-11$ & $4.28 \mathrm{E}-11$ & $9.99 \mathrm{E}-11$ & $2.50 \mathrm{E}-10$ & $2.37 \mathrm{E}-10$ & $2.60 \mathrm{E}-10$ \\
\hline 17 & $1.40 \mathrm{E}-12$ & $2.19 \mathrm{E}-12$ & $4.32 \mathrm{E}-12$ & $9.43 \mathrm{E}-12$ & $2.19 \mathrm{E}-11$ & $5.44 \mathrm{E}-11$ & $5.00 \mathrm{E}-11$ & $5.30 \mathrm{E}-11$ \\
\hline 18 & $4.09 \mathrm{E}-12$ & $6.39 \mathrm{E}-12$ & $1.26 \mathrm{E}-11$ & $2.74 \mathrm{E}-11$ & $6.33 \mathrm{E}-11$ & $1.57 \mathrm{E}-10$ & $1.42 \mathrm{E}-10$ & $1.49 \mathrm{E}-10$ \\
\hline 19 & $9.76 \mathrm{E}-12$ & $1.52 \mathrm{E}-11$ & $2.99 \mathrm{E}-11$ & $6.51 \mathrm{E}-11$ & $1.51 \mathrm{E}-10$ & $3.74 \mathrm{E}-10$ & $3.36 \mathrm{E}-10$ & $3.51 \mathrm{E}-10$ \\
\hline$i$ & $1.19 \mathrm{E}-09$ & $1.66 \mathrm{E}-09$ & $2.80 \mathrm{E}-09$ & $5.25 \mathrm{E}-09$ & $1.05 \mathrm{E}-08$ & $2.30 \mathrm{E}-08$ & $2.07 \mathrm{E}-08$ & $1.89 \mathrm{E}-08$ \\
\hline
\end{tabular}

\begin{tabular}{llllllll} 
Initial states & \multicolumn{7}{c}{ Final states } \\
\cline { 2 - 8 } & 14 & 15 & \multicolumn{7}{c}{17} & 18 & 19 & $i$ \\
6 & $3.26 \mathrm{E}-13$ & $2.04 \mathrm{E}-13$ & $1.89 \mathrm{E}-13$ & $1.78 \mathrm{E}-13$ & $1.73 \mathrm{E}-13$ & $1.72 \mathrm{E}-13$ & $3.33 \mathrm{E}-13$ \\
7 & $2.78 \mathrm{E}-12$ & $1.73 \mathrm{E}-12$ & $1.59 \mathrm{E}-12$ & $1.49 \mathrm{E}-12$ & $1.44 \mathrm{E}-12$ & $1.43 \mathrm{E}-12$ & $2.48 \mathrm{E}-12$ \\
8 & $6.92 \mathrm{E}-13$ & $4.25 \mathrm{E}-13$ & $3.88 \mathrm{E}-13$ & $3.61 \mathrm{E}-13$ & $3.50 \mathrm{E}-13$ & $3.48 \mathrm{E}-13$ & $5.16 \mathrm{E}-13$ \\
9 & $1.19 \mathrm{E}-12$ & $7.24 \mathrm{E}-13$ & $6.57 \mathrm{E}-13$ & $6.07 \mathrm{E}-13$ & $5.87 \mathrm{E}-13$ & $5.83 \mathrm{E}-13$ & $7.46 \mathrm{E}-13$ \\
10 & $8.59 \mathrm{E}-12$ & $5.13 \mathrm{E}-12$ & $4.62 \mathrm{E}-12$ & $4.25 \mathrm{E}-12$ & $4.10 \mathrm{E}-12$ & $4.07 \mathrm{E}-12$ & $4.52 \mathrm{E}-12$ \\
11 & $3.93 \mathrm{E}-11$ & $2.31 \mathrm{E}-11$ & $2.07 \mathrm{E}-11$ & $1.89 \mathrm{E}-11$ & $1.81 \mathrm{E}-11$ & $1.80 \mathrm{E}-11$ & $1.76 \mathrm{E}-11$ \\
12 & $6.02 \mathrm{E}-10$ & $3.11 \mathrm{E}-10$ & $2.70 \mathrm{E}-10$ & $2.38 \mathrm{E}-10$ & $2.26 \mathrm{E}-10$ & $2.23 \mathrm{E}-10$ & $2.18 \mathrm{E}-10$ \\
13 & $3.23 \mathrm{E}-09$ & $1.34 \mathrm{E}-09$ & $1.12 \mathrm{E}-09$ & $9.57 \mathrm{E}-10$ & $8.97 \mathrm{E}-10$ & $8.81 \mathrm{E}-10$ & $7.52 \mathrm{E}-10$ \\
14 & - & $2.05 \mathrm{E}-10$ & $1.62 \mathrm{E}-10$ & $1.34 \mathrm{E}-10$ & $1.24 \mathrm{E}-10$ & $1.21 \mathrm{E}-10$ & $9.32 \mathrm{E}-11$ \\
15 & $1.36 \mathrm{E}-10$ & - & $1.36 \mathrm{E}-10$ & $8.85 \mathrm{E}-11$ & $7.83 \mathrm{E}-11$ & $7.40 \mathrm{E}-11$ & $4.61 \mathrm{E}-11$ \\
16 & $3.25 \mathrm{E}-10$ & $4.10 \mathrm{E}-10$ & - & $3.55 \mathrm{E}-10$ & $2.95 \mathrm{E}-10$ & $2.69 \mathrm{E}-10$ & $1.46 \mathrm{E}-10$ \\
17 & $6.39 \mathrm{E}-11$ & $6.35 \mathrm{E}-11$ & $8.46 \mathrm{E}-11$ & - & $9.71 \mathrm{E}-11$ & $8.00 \mathrm{E}-11$ & $3.66 \mathrm{E}-11$ \\
18 & $1.78 \mathrm{E}-10$ & $1.68 \mathrm{E}-10$ & $2.11 \mathrm{E}-10$ & $2.91 \mathrm{E}-10$ & - & $3.31 \mathrm{E}-10$ & $1.18 \mathrm{E}-10$ \\
19 & $4.16 \mathrm{E}-10$ & $3.82 \mathrm{E}-10$ & $4.61 \mathrm{E}-10$ & $5.75 \mathrm{E}-10$ & $7.92 \mathrm{E}-10$ & - & $3.09 \mathrm{E}-10$ \\
$i$ & $2.02 \mathrm{E}-08$ & $1.50 \mathrm{E}-08$ & $1.57 \mathrm{E}-08$ & $1.66 \mathrm{E}-08$ & $1.78 \mathrm{E}-08$ & $1.95 \mathrm{E}-08$ & -
\end{tabular}

well separated groups of molecular states in $\mathrm{LiH}^{+}$. Apart from the first group which includes the $\mathrm{LiH}^{+}$ground state as well as an infinite number of Rydberg-like excited states $\mathrm{Li}^{+}\left(1 s^{2}\right)+\mathrm{H}(n l)$ and $\mathrm{Li}\left(1 s^{2} n l\right)+\mathrm{H}^{+}$, the second group of scattering channels, as listed in Table 2, consists of $\mathrm{Li}^{+}(1 s n l)+\mathrm{H}$ states $(n \geq 2)$ plus the ion-pair state $\mathrm{Li}^{2+}+\mathrm{H}^{-}$. Because of the large energy gap between the two groups, nonadiabatic transitions between molecular states from the different groups can be neglected. Nonadiabatic transitions between low-lying states in the first group have been studied previously by $[15,16]$, as mentioned above. The present study of inelastic $\mathrm{Li}^{2+}+\mathrm{H}^{-}$ and $\mathrm{Li}^{+}+\mathrm{H}$ collisions is performed for 35 scattering channels leading to the 34 excited $\mathrm{Li}^{+}\left(1 s n l^{1,3} L\right)$ states $(n \geq 2)$ below the $\mathrm{Li}^{2+}$ ionization limit interacting with the hydrogen atom, as well as the ionic pair $\mathrm{Li}^{2+}+\mathrm{H}^{-}$in its ground state (Tab. 2). Like in the case of $\mathrm{LiH}^{2+}$, quasi-stationary widths of the treated molecular states are negligible.
The asymptotic model adiabatic potentials for the $\mathrm{LiH}^{+}\left({ }^{2} \Sigma^{+}\right)$molecule are plotted in Figure 5. A series of avoided crossings due to the ionic-covalent interactions is clearly seen. Landau-Zener parameters in each nonadiabatic region are determined using the adiabaticpotential-based formula $[17,28]$ followed by calculations of nonadiabatic transition probabilities with the multichannel formula [24,26]. Inelastic cross sections and rate coefficients for the recombination processes due to the transitions between the states listed in Table 2 are then calculated as usual.

The temperature dependences of rate coefficients with large and moderate values for the charge recombination processes in $\mathrm{Li}^{2+}+\mathrm{H}^{-}$collisions are plotted in Figure 6 . In the upper part of the figure there is a series of partial processes with high rate coefficients which correspond to the recombination processes into the final states $\mathrm{Li}^{+}\left(1 s 3 d{ }^{1} D\right), \mathrm{Li}^{+}\left(1 s 3 p{ }^{1} P\right), \mathrm{Li}^{+}\left(1 s 4 s^{1,3} S\right)$, 


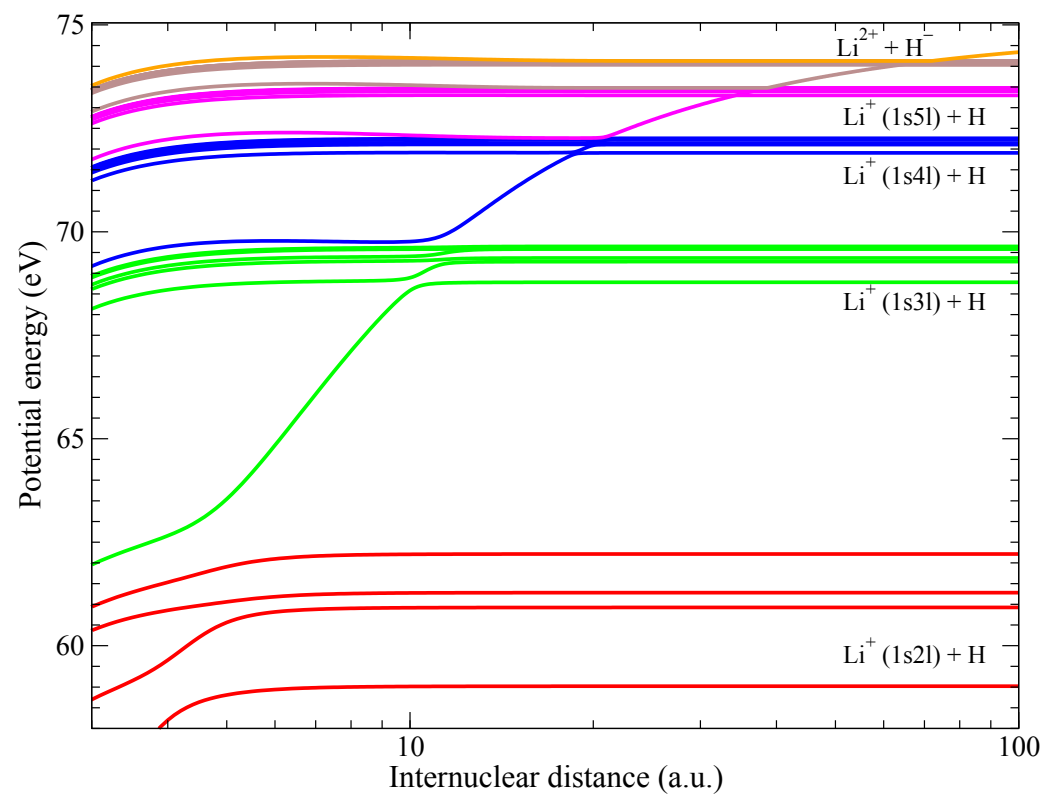

Fig. 5. The $\mathrm{LiH}^{+}\left({ }^{2} \Sigma^{+}\right)$adiabatic potential energy curves obtained by means of the model approach. The potentials are measured from the ground state asymptote. The potential channels are defined in Table 2.

$\mathrm{Li}^{+}\left(1 s 4 p^{1,3} P\right), \mathrm{Li}^{+}\left(1 s 4 d^{1,3} D\right), \mathrm{Li}^{+}\left(1 s 4 f^{1,3} F\right)$. The rate coefficient values of these recombination processes are of the order of magnitude of $10^{-8} \mathrm{~cm}^{3} / \mathrm{s}$. Actual numerical values for these rate coefficients at temperature $T=10000 \mathrm{~K}$ are summarized in Table 4. Below this group a number of recombination processes with moderate rate coefficients appear, with values between $10^{-10}$ and $10^{-8} \mathrm{~cm}^{3} / \mathrm{s}$. Other rate coefficients with values smaller than $10^{-10} \mathrm{~cm}^{3} / \mathrm{s}$ are not shown in the figure. The calculated partial rate coefficients for all processes in ionic-lithium-hydrogen collisions between the states listed in Table 2 are available online as supplementary materials to this paper. For the total recombination rate coefficient (the thick black curve) at temperature $T=$ $10000 \mathrm{~K}$ a value equal to $2 \times 10^{-7} \mathrm{~cm}^{3} / \mathrm{s}$ is obtained, which practically coincides with the total recombination rate coefficient in $\mathrm{Li}^{3+}+\mathrm{H}^{-}$collisions.

Like in the $\mathrm{LiH}^{2+}$ collisional system, rate coefficients for the ion-pair formation, excitation and de-excitation processes are smaller than their recombination analogs. Differences however are not as large here. According to Table 4 and Figure 7, the highest rate coefficients for ionpair formation, excitation and de-excitation processes in the $\mathrm{LiH}^{+}$system are only about one order of magnitude smaller compared to the largest recombination rate coefficients. This is due to smaller energy defects in the $\mathrm{LiH}^{+}$ collisional system compared to the $\mathrm{LiH}^{2+}$ system. Determinations of the ion-pair formation rate coefficients $K_{f i}$ are done again applying relation (1), using the corresponding recombination rate coefficients $K_{i f}$. Since the energy thresholds $\Delta E_{i f}$ are here not as large as for similar processes in $\mathrm{Li}^{2+}(n l)+\mathrm{H}$ collisions, ion-pair formation rate coefficients in $\mathrm{Li}^{+}(1 s n l)+\mathrm{H}$ collisions are obtained with larger values (Fig. 7). For higher temperatures several partial ion-pair formation rate coefficients in $\mathrm{Li}^{+}(1 s n l)+\mathrm{H}$ collisions can become larger than $10^{-9} \mathrm{~cm}^{3} \mathrm{~s}^{-1}$ which is roughly an order of magnitude higher than in $\mathrm{Li}^{2+}(n l)+\mathrm{H}$ collisions (Fig. 4).

The high rate coefficient values obtained here show that charge recombination and the inverse processes, ion-pair formation, in $\mathrm{Li}^{2+}+\mathrm{H}^{-}$and $\mathrm{Li}^{+}(1 s n l)+\mathrm{H}$ collisions are efficient in producing $\mathrm{Li}^{+}$ions, as well as $\mathrm{H}^{-}$anions. Therefore, like in $\mathrm{Li}^{3+}+\mathrm{H}^{-}$and $\mathrm{Li}^{2+}(n l)+\mathrm{H}$ collisions, it can be guessed that at high $\mathrm{H}^{-}$abundances the charge recombination $\mathrm{Li}^{2+}+\mathrm{H}^{-} \rightarrow \mathrm{Li}^{+}(1 s n l)+\mathrm{H}$ can effectively produce excited lithium ions $\mathrm{Li}^{+}(1 s 3 l, 1 s 4 l)$ which quickly cascade down to ground-state ions $\mathrm{Li}^{+}\left(1 s^{2}\right)$, where mutual neutralization in collisions with hydrogen negative ions finally results in production of lithium atoms. If the abundance of $\mathrm{H}^{-}$is low, electron recombination processes can create excited ions $\mathrm{Li}^{+}(1 s n l)$ which through collisions with neutral hydrogen atoms can efficiently increase the abundance of $\mathrm{H}^{-}$anions due to high rate coefficients of the ion-pair formation processes. The same expectations can therefore be formulated as in the case of $\mathrm{Li}^{3+}+\mathrm{H}^{-}$ and $\mathrm{Li}^{2+}(n l)+\mathrm{H}$ collisions, that formation of lithium ions and atoms as well as production of hydrogen negative ions could be influenced by the present collisional processes.

\section{Conclusion}

Inelastic processes in low-energy collisions in the systems $\mathrm{Li}^{3+}+\mathrm{H}^{-}, \mathrm{Li}^{2+}+\mathrm{H}$ and $\mathrm{Li}^{2+}+\mathrm{H}^{-}$and $\mathrm{Li}^{+}+\mathrm{H}$ are investigated for all collisional channels with the excited ionic lithium states $\mathrm{Li}^{2+}(n l)$ and $\mathrm{Li}^{+}(1 s n l)$ up to and including the corresponding ion-pair states. Since the collision potentials between hydrogen and the highly excited lithium ions considered here are not accessible by rigorous ab initio calculations, a model potential approach 


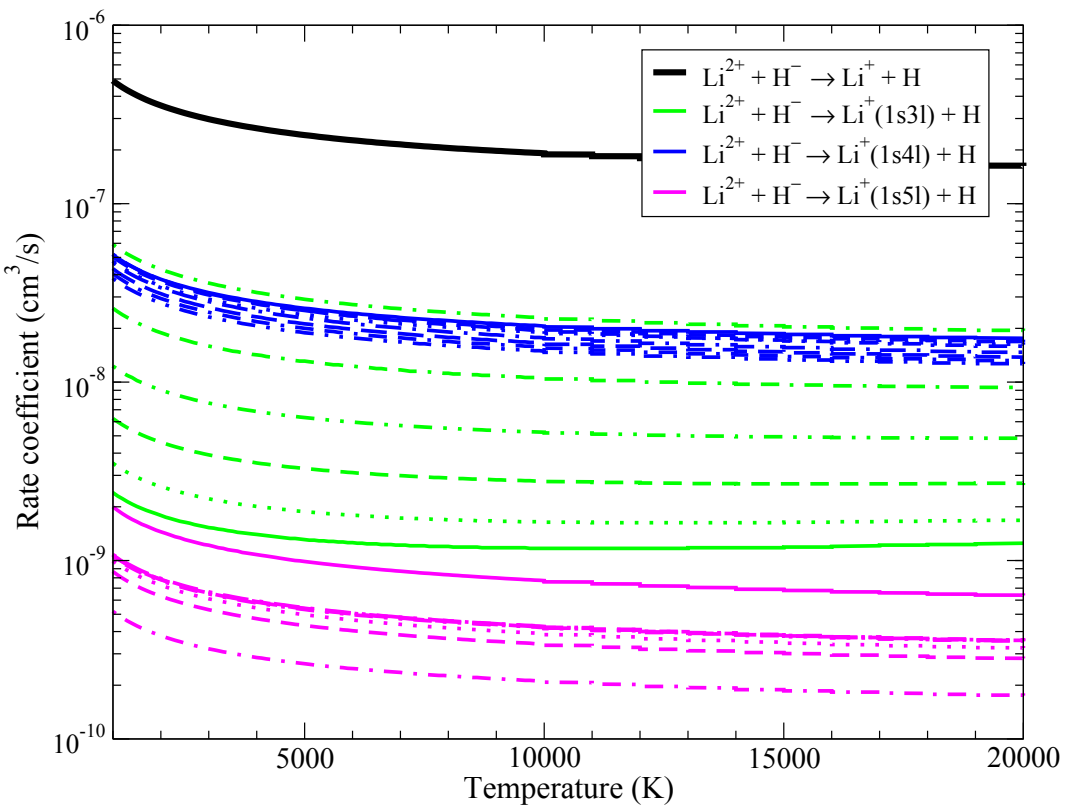

Fig. 6. Partial rate coefficients for recombination processes in $\mathrm{Li}^{2+}+\mathrm{H}^{-}$collisions with high and moderate values. The thick black line shows the total recombination rate coefficient. The initial channel is ionic. For the final channels, solid curves represent $\mathrm{Li}^{+}\left(1\right.$ sns $\left.{ }^{3} S\right)+\mathrm{H}$ states, dotted curves $\mathrm{Li}^{+}\left(1\right.$ sns $\left.{ }^{1} S\right)+\mathrm{H}$, dashed curves $\mathrm{Li}^{+}\left(1\right.$ snp $\left.{ }^{3} P\right)+\mathrm{H}$, dot-dashed curves Li ${ }^{+}\left(1\right.$ snp $\left.{ }^{1} P\right)+\mathrm{H}$, double-dot-dashed curves $\mathrm{Li}^{+}\left(1\right.$ snd $\left.{ }^{3} D\right)+\mathrm{H}$, dot-double-dashed curves $\mathrm{Li}^{+}\left(1\right.$ snd $\left.{ }^{1} D\right)+\mathrm{H}$, long-dashed curves Li ${ }^{+}\left(1\right.$ snf $\left.{ }^{3} F\right)+\mathrm{H}$, dot-long-dashed curves $\mathrm{Li}^{+}\left(1\right.$ snf $\left.{ }^{1} F\right)+\mathrm{H}$.

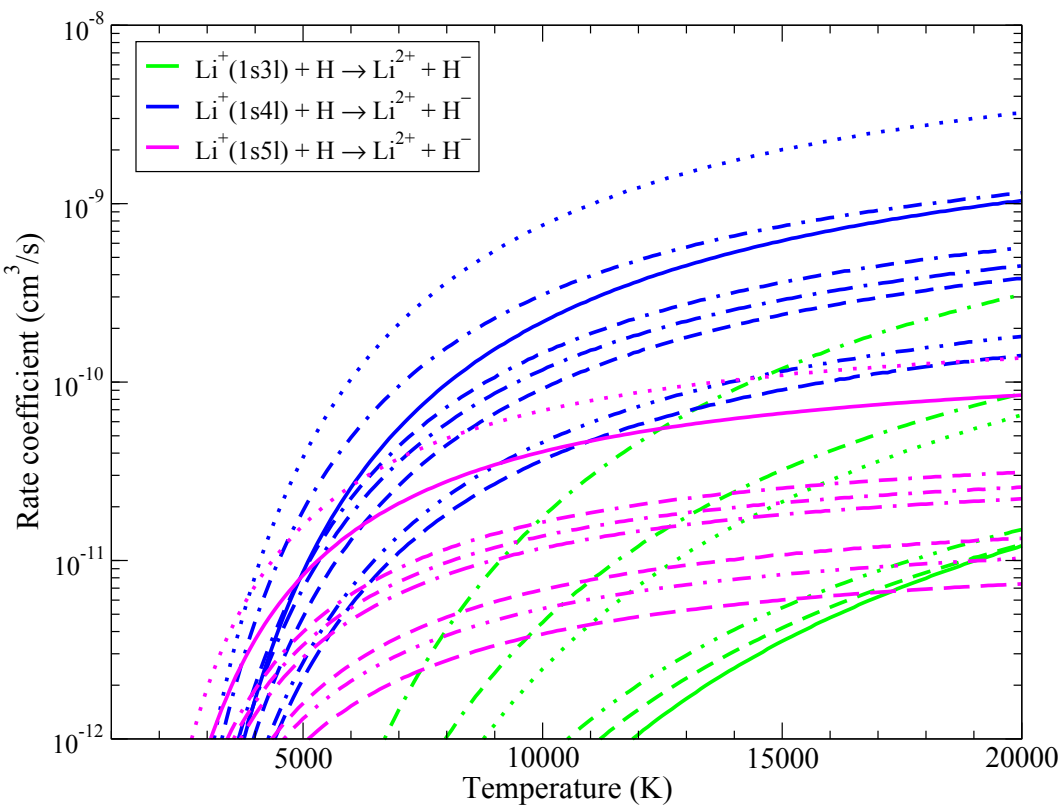

Fig. 7. The partial rate coefficients for ion-pair formation processes in $\mathrm{Li}^{+}(1 s n l)+\mathrm{H}$ collisions. The labels for the initial channels are the same as in Figure 6 for the final channels of the recombination processes.

is applied. Based on the long-range asymptotic adiabatic potentials the multichannel model is employed. Nonadiabatic transition probabilities in each nonadiabatic region are calculated within the Landau-Zener model using the adiabatic-potential-based formula. Inelastic cross sections are obtained and used to calculate rate coefficients for recombination, ion-pair formation, excitation and deexcitation processes.

For both collisional systems total rate coefficients for the charge recombination processes are determined with maximum values between $10^{-7} \mathrm{~cm}^{3} / \mathrm{s}$ and $10^{-6} \mathrm{~cm}^{3} / \mathrm{s}$ over a wide temperature range at least up to $T=20000 \mathrm{~K}$. 
In case of the inverse, ion-pair formation, processes rate coefficients in both collisional systems start for temperatures much below $T=1000 \mathrm{~K}$ at small values due to their endothermicity, but with increasing temperatures the rate coefficients for several partial processes are rapidly increasing reaching maximum values of the order of $10^{-10}-10^{-9} \mathrm{~cm}^{3} / \mathrm{s}$ at temperatures close to $T=20000 \mathrm{~K}$.

With their large rate coefficient values the charge recombinations and their inverse processes, the ion-pair formations, are thus found to be very efficient in producing lithium cations and/or hydrogen anions in both collisional systems discussed here. But in spite of this finding, the probability that the formation of $\mathrm{Li}^{Z+}$ and $\mathrm{H}^{-}$ions in interstellar or stellar-atmosphere environments could be influenced by these collisional processes is very low due to the fact that under conditions where the multiply charged lithium ions exist the $\mathrm{H}^{-}$ions are readily destroyed. We assume that the present results are important from a fundamental point of view, most likely the results on the charge recombination constitute useful predictions for possible upcoming experiments, as well as possible applications, and therefore, the rate coefficients are calculated and presented for all processes in the considered collisions for completeness of the data.

A.K.B. and S.A.Y. gratefully acknowledge partial support from the Max-Planck Institute for Astrophysics (Garching, Germany) and partial support from the Russian Science Foundation (Russian Federation) [Grant No. 17-13-01144]. S.A.Y. also gratefully acknowledges partial support from the Dynasty Foundation (Russian Federation). Open access funding provided by Max Planck Society.

\section{Author contribution statement}

All the authors were involved in the preparation of the manuscript. All the authors have read and approved the final manuscript. All the authors equally contributed into the present work.

Open Access This is an open access article distributed under the terms of the Creative Commons Attribution License (http://creativecommons.org/licenses/by/4.0), which permits unrestricted use, distribution, and reproduction in any medium, provided the original work is properly cited.

\section{References}

1. R. Morgenstern, T. Schlatholter, R. Hoekstra, in The Physics of Electronic and Atomic Collisions (21st International Conference on the Physics of Electronic and Atomic Collisions (21st ICPEAC), Sendai, Japan, 1999) (2000), Vol. 500, pp. 65-84

2. G. Lubinski, Z. Juhasz, R. Morgenstern, R. Hoekstra, Phys. Rev. Lett. 86, 616 (2001)
3. U. Kadhane, D. Misra, Y.P. Singh, L.C. Tribedi, Phys. Rev. Lett. 90, 093401 (2003)

4. R.D. Thomas, H.T. Schmidt, G. Andler et al., Rev. Sci. Instrum. 82, 065112 (2011)

5. H.T. Schmidt, R.D. Thomas, M. Gatchell et al., Rev. Sci. Instrum. 84, 055115 (2013)

6. R. von Hahn, A. Becker, F. Berg, K. Blaum, C. Breitenfeldt, H. Fadil, F. Fellenberger, M. Froese, S. George, J. Göck et al., Rev. Sci. Instrum. 87, 063115 (2016)

7. Y. Nakano, Y. Enomoto, T. Masunaga, S. Menk, P. Bertier, T. Azuma, Rev. Sci. Instrum. 88, 033110 (2017)

8. M. Asplund, Annu. Rev. Astron. Astrophys. 43, 481 (2005)

9. L. Mashonkina, IAU Symp. 298, 355 (2014)

10. P.S. Barklem, Astron. Astrophys. Rev. 24, 1 (2016)

11. P.S. Barklem, A.K. Belyaev, M. Asplund, Astron. Astrophys. 409, L1 (2003)

12. H. Croft, A.S. Dickinson, F.X. Gadéa, J. Phys. B: At. Mol. Opt. Phys. 32, 81 (1999)

13. H. Croft, A.S. Dickinson, F.X. Gadéa, MNRAS 304, 327 (1999)

14. A.K. Belyaev, P.S. Barklem, Phys. Rev. A 68, 062703 (2003)

15. L. Liu, C.H. Liu, G. Wang, R.K. Janev, Phys. Rev. A 84, $032710(2011)$

16. L. Yan, Y. Qu, C. Liu, J. Wang, R.J. Buenker, J. Chem. Phys. 136, 124304 (2012)

17. A.K. Belyaev, Phys. Rev. A 88, 052704 (2013)

18. A.K. Belyaev, J. Grosser, J. Hahne, T. Menzel, Phys. Rev. A 60, 2151 (1999)

19. A.K. Belyaev, P.S. Barklem, A.S. Dickinson, F.X. Gadéa, Phys. Rev. A 81, 032706 (2010)

20. J.Z. Mezei, J.B. Roos, K. Shilyaeva, N. Elander, Å. Larson, Phys. Rev. A 84, 012703 (2011)

21. A.K. Belyaev, P.S. Barklem, A. Spielfiedel, M. Guitou, N. Feautrier, D.S. Rodionov, D.V. Vlasov, Phys. Rev. A 85, $032704(2012)$

22. M. Guitou, A. Spielfiedel, D.S. Rodionov, S.A. Yakovleva, A.K. Belyaev, T. Merle, F. Thévenin, N. Feautrier, Chem. Phys. 462, 94 (2015)

23. A.K. Belyaev, S.I. Tserkovnyi, Opt. Spektrosk. 63, 968 (1987)

24. A.K. Belyaev, Phys. Rev. A 48, 4299 (1993)

25. A.K. Belyaev, S.A. Yakovleva, P.S. Barklem, Astron. Astrophys. 572, A103 (2014)

26. S.A. Yakovleva, Y.V. Voronov, A.K. Belyaev, Astron. Astrophys. 593, A27 (2016)

27. A. Mitrushchenkov, M. Guitou, A.K. Belyaev, S.A. Yakovleva, A. Spielfiedel, N. Feautrier, J. Chem. Phys. 246, 014304 (2017)

28. A.K. Belyaev, O.V. Lebedev, Phys. Rev. A 84, 014701 (2011)

29. A. Kramida, Y. Ralchenko, J. Reader, NIST ASD Team, in NIST Atomic Spectroscopy Database, Version 5.0 (National Institute of Standards and Technology, Gaithersburg, 2012), http://physics.nist.gov/asd

30. M. Satta, T. Grassi, F.A. Gianturco, S.A. Yakovleva, A.K. Belyaev, Mon. Not. R. Astron. Soc. 436, 2722 (2013) 